\title{
Formation and Properties of Nylon 6 Nanocomposites
}

\author{
T. D. Fornes, D. R. Paul \\ Department of Chemical Engineering and Texas Materials Institute, The University of Texas at Austin
}

\begin{abstract}
Sodium montmorillonite clay consists of platelets, one nanometer thick with large lateral dimensions, which can be used to achieve efficient reinforcement of polymer matrices. Formation of these nanocomposites requires modifying the clay with an appropriate organic surface treatment and optimized processing. Some of these techniques and the resulting property improvements (modulus, thermal expansion, heat distortion temperature, etc.) are reviewed here. It is shown that shear stress exerted on stacks of clay platelets play an important role in the mechanism of exfoliation. The modulus enhancement observed is of the order predicted by composite theories; however, the clay particles clearly affect the crystalline morphology of the polymer phase which may have an additional effect on some composite properties.
\end{abstract}

Keywords: Nanocomposites, nylon 6, organoclay, melt processing.

\section{Introduction}

Polymer-layered silicate nanocomposites formed from the organically modified clay mineral montmorillonite and related materials have attracted a great deal of technological and scientific interest ${ }^{[1-3]}$. These composites offer the promise of greatly improved properties over those of the matrix polymer owing to the nanoscale reinforcement and constraints of the polymer caused by dispersing the $1 \mathrm{~nm}$ thick, high aspect ratio aluminosilicate layers. The property enhancements that could be readily anticipated and some that were not obvious have driven the excitement about nanocomposites. However, commercialization of these materials has been limited by the lack of knowledge about formation of nanocomposites using practical and economical processes and by some other unsolved problems.

Numerous benefits of nanocomposites formed from a variety of matrix polymers have been described. The property improvements can generally be divided into the following areas: mechanical properties, heat resistance, dimensional stability, barrier and flame retardation. The potential property improvements usually depend on the degree of delamination and dispersion, which as shown here depends on a combination of the proper chemical treatment and optimized processing. These effects are illustrated here using recent results obtained from nanocomposites based on a nylon 6 matrix.

\section{Organoclays and terminology}

The aluminosilicate layers of montmorillonite, MMT, have a net negative charge and in the native state the counter ion is typically sodium as shown by the structural schematic in Figure $1^{[4]}$. To make these platelets more compatible with polymers, the sodium ions are exchanged with alkyl ammonium ions to produce an organoclay. Figure 2 shows a sampling of the organic amine structures used to make the organoclays and a simple short-hand nomenclature system for identifying these molecules. The ammonium ion usually has one or two alkyl tails formed from naturally occurring oils, e.g., $\mathrm{C}=\operatorname{cocoa}\left(\mathrm{C}_{12}\right), \mathrm{T}=$ tallow $\left(\mathrm{C}_{18}\right)$, $\mathrm{R}=$ rapeseed $\left(\mathrm{C}_{22}\right)$, etc. These tails have some level of unsaturation (double bonds) in the native form but may be hydrogenated $(\mathrm{H})$. Other groups on the nitrogen may be hydrogen, methyl (M), hydroxyethyl (HE), benzyl (BZ), etc. The X-ray d-spacing between MMT platelets increases as the size of organic cation increases as illustrated in Figure $3^{[5]}$. These organoclays were provided for this research by Southern Clay Products of Gonzales, Texas.

Unlike the more common clay minerals used as fillers for plastics, such as talc and mica, MMT can be delaminated and dispersed into individual layers of only $10 \AA$ thickness. Unseparated MMT layers, after introduction into the polymer, are often referred to as tactoids ${ }^{[6]}$. The term intercalation describes the case where a small amount of polymer moves into the gallery spacing between the clay platelets, but causes less than $20-30 \AA$ separation between the platelets. Exfoliation or delamination occurs when polymer further

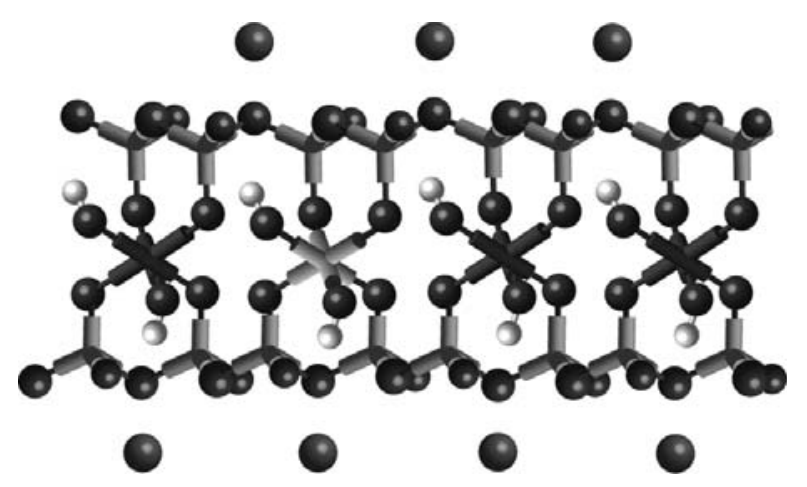

Figure 1. Structure of sodium montmorillonite.

Autor para Correspondência: D. R. Paul, Department of Chemical Engineering and Texas Materials Institute, The University of Texas at Austin, Austin TX 78712, USA.E-mail:drp@che.utexas.edu 


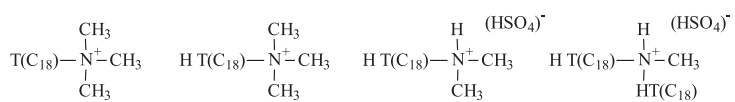

$$
\begin{aligned}
& \mathrm{M}_{3} \mathrm{~T}_{1} \quad \mathrm{M}_{3}(\mathrm{HT})_{1} \quad \mathrm{M}_{2}(\mathrm{HT})_{1} \quad \mathrm{M}_{1} \mathrm{H}_{1}(\mathrm{HT})_{2}
\end{aligned}
$$

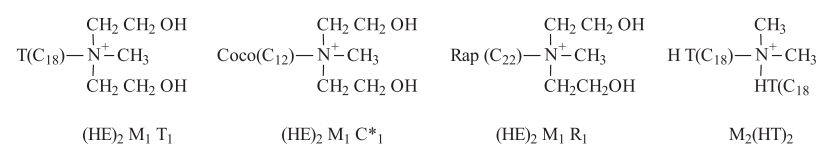

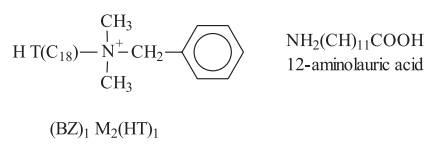

Figure 2. Structure of some organic amines used to form organoclays by ion exchange with sodium montmorillonite

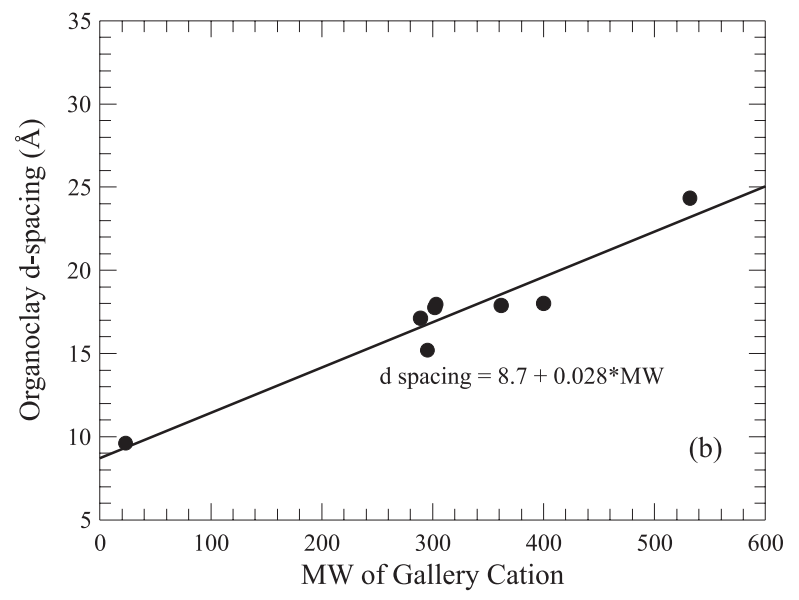

Figure 3. Effect of gallery cation size on organoclay d-spacing.

separates the clay platelets, e.g., by $80-100 \AA$ or more. A well-delaminated and dispersed nanocomposite as defined in this paper, consists of delaminated platelets distributed homogeneously in the polymer. These terms are shown schematically in Figure 4.

\section{Processing}

Vaia and Giannelis ${ }^{[7,8]}$ have shown that, with appropriate thermodynamic interactions, polymers can spontaneously intercalate the galleries of organoclays; however, it appears that static diffusion alone cannot lead to full exfoliation. However, in combination with appropriate chemical or mechanical processes, exfoliation is possible. The key issue for making nanocomposite technology broadly useful is to understand how to select processes, materials, and conditions that achieve optimum performance for specific systems.

A pivotal event in the development of this technology was the disclosure by Toyota of an improved method for producing nylon 6/clay nanocomposites using an in situ polymerization process that effectively exfoliates the aluminosilicate layers by an easily understood chemical mechanism ${ }^{[9]}$. Since then, similar chemical strategies have been described for many thermoplastic and thermoset polymers. The Toyota process is
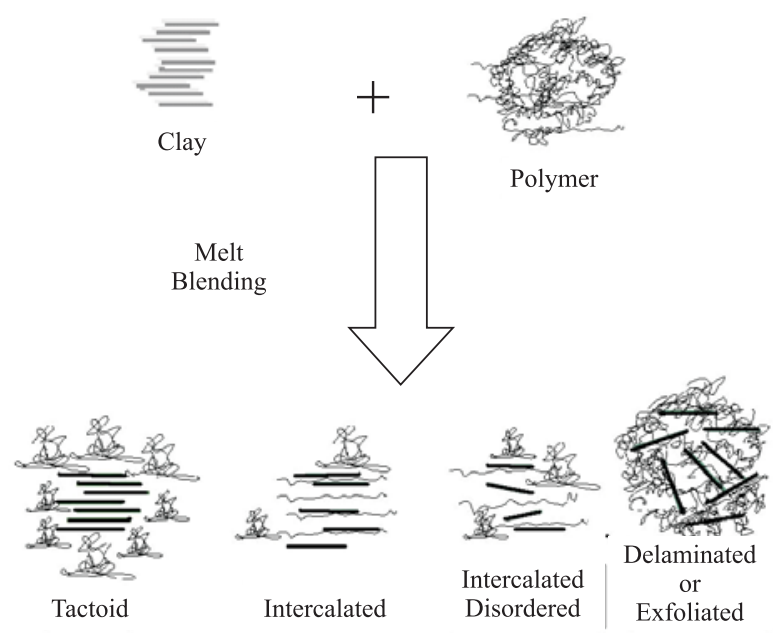

Figure 4. Schematic illustration of terminology used to describe nanocomposites formed from organoclays.

illustrated schematically in Figure 5. Sodium montmorillonite is mixed with an $\alpha, \omega$-amino acid (e.g., aminolauric acid) in aqueous hydrochloric acid to protonate the aminolauric acid which then can exchange with the sodium counterions; thus, the alkyl units of the resulting organoclay has terminal carboxyl groups. Under appropriate reaction conditions, the carboxyl groups on the organoclay will initiate ring-opening polymerization of caprolactam to form nylon 6 chains ionically bonded to the aluminosilicate platelets. The growth of these chains, driven by the free energy of polymerization, forces the platelets apart until exfoliation is accomplished.

Clearly, nanocomposites might be more widely used if they could be formed from existing polymers using conventional melt processing techniques (extrusion, injection molding, etc.).

Nylon 6 Nanocomposites by in situ Polymerization

Toyota Process for $\mathrm{NCH}=$ nylon 6 - clay hybrids
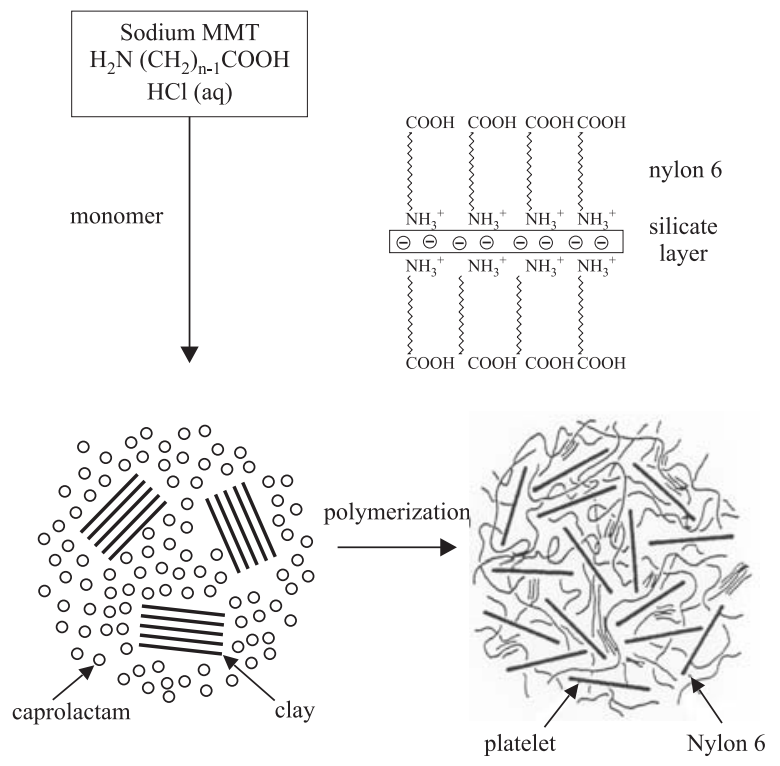

Figure 5. Formation of nylon 6 nanocomposites by in situ polymerization (Toyota Process). 
Indeed, nanocomposites have been formed using a variety of shear devices (e.g., extruders, mixers, ultrasonicators, etc.). Of these melt processing techniques, twin screw extrusion has proven to be most effective for the exfoliation and dispersion of silicate layers. Owing to the combination of shear and good polymer-organoclay affinity, twin screw extrusion leads to composite properties comparable to those produced by in-situ techniques ${ }^{[10]}$. The advantages of forming nanocomposites by melt processing are quite appealing. The process is environmentally sound since no solvents are required. It shifts nanocomposite production downstream, thereby giving enduse manufacturers many degrees of freedom with regard to final product specifications (e.g., selection of polymer grade, choice of organoclay, level of reinforcement, etc.). At the same time, melt processing minimizes capital costs due to its compatibility with existing processes.

Recent studies have demonstrated that melt processing conditions play a key role in achieving high levels of exfoliation ${ }^{[11]}$. Results from these studies indicate that an optimum balance between residence time and level of shear is required to facilitate the exfoliation and dispersion of layered silicates. In addition, proper choice of organoclay chemistry is critical. For example, for nylon 6, the surfactants in Figure 2 that have only one alkyl tail give better exfoliation than those with $\mathrm{two}^{[5]}$.

\section{Stress-strain properties}

One of the demonstrated benefits of adding high aspect ratio, nanoscale platelets to polymers is a large increase in stiffness or modulus per unit mass of reinforcement (i.e., a beneficial stiffness/weight ratio). This also translates into higher strength, hardness and possibility mar or scratch resistance. The extent of the enhancement is directly related to the degree of exfoliation. For nylon 6, recent research has demonstrated that comparable levels of exfoliation and performance, at least in terms of stress-strain behavior, can be achieved by melt processing as found by the chemical approach $^{[10]}$. A surprising result from this research is that the degree of exfoliation of a typical organoclay, the one derived

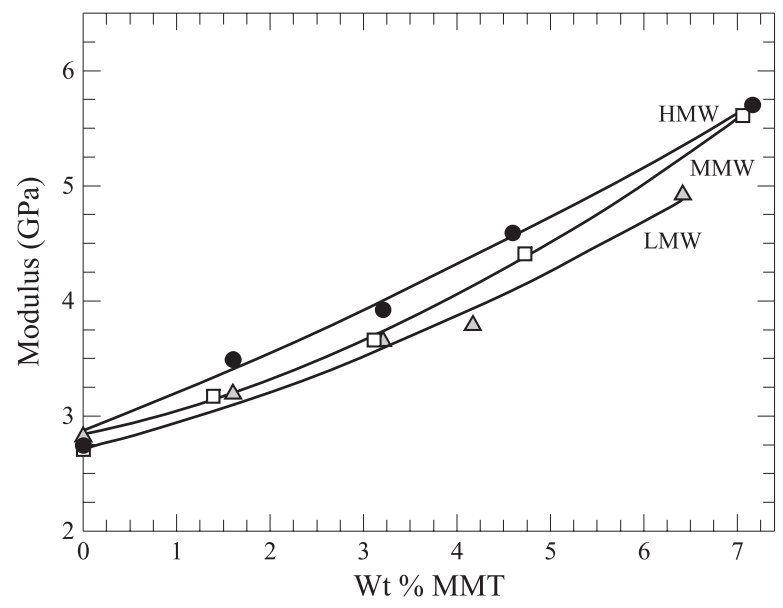

Figure 6. Modulus of nanocomposites made by melt processing showing effect of the molecular weight of the nylon 6 matrix and content of montmorillonite (weight $\%$ of MMT).

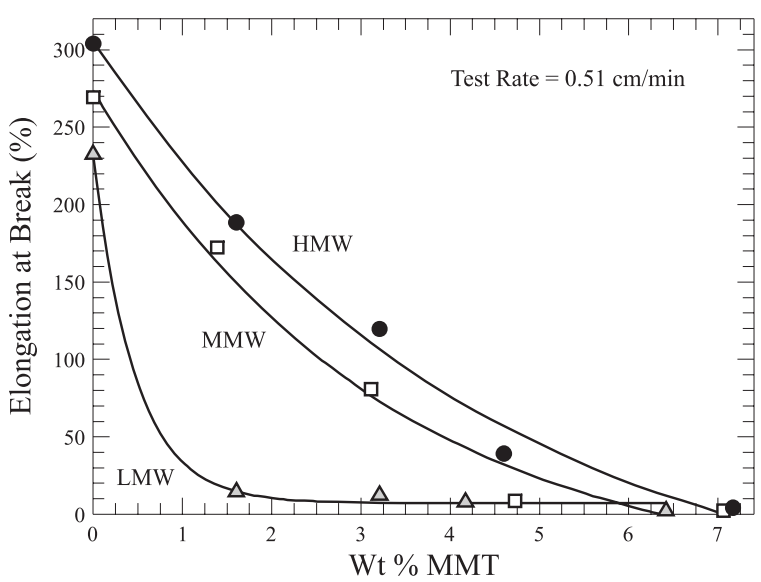

Figure 7. Elongation at break as a function of montmorillonite content of nanocomposites formed from the three molecular weight grades of nylon 6 (see Figure 6).

from $(\mathrm{HE})_{2} \mathrm{M}_{1} \mathrm{R}_{1}$, by melt processing improves as the molecular weight of the nylon 6 matrix is increased ${ }^{[12,13]}$. Some evidence for this is seen in Figure 6 which shows higher levels of modulus, at a given loading of MMT, as the molecular weight of the nylon 6 increases. Both wide angle x-ray scattering, WAXS, and transmission electron microscopy, TEM, evidence support the notion that these property improvements stem from better exfoliation. On the other hand, one might expect a corresponding decrease in ductility, e.g., elongation at break. However, with appropriate processing and materials choices, ductility (as judged by the ability to elongate well beyond the yield point in tensile tests) can be preserved to high organoclay loadings as shown in Figure 7 for nylon 6 .

Many of the responses observed can be explained in terms of simple reinforcement and modeled by theories of composites as shown later; however, it is important to appreciate that additional effects caused by matrix-filler interactions, including changes in matrix crystal structure or chain mobility, may also be involved because of the high surface areas and small dimensions.

\section{Mechanism of exfoliation in melt processing}

The increase in exfoliation during melt processing as the nylon 6 molecular weight is increased is totally inconsistent with a diffusion limited mechanism. There is strong evidence that this effect stems from the higher melt viscosity which imposes higher shear stresses during melt mixing in the extruder. The preliminary picture (see Figure 8) is that stresses in the extruder break the organoclay particles into stacks of platelets or tactoids which can be subsequently sheared apart to make smaller platelet stacks. Shear stresses are an important element in these events. Finally, TEM evidence suggests that the platelets on the surface peel apart by a combination of diffusion of polymer chains and shear which is aided by the fact that individual platelets are not rigid but are quite able to bend away as suggested in Figure 8. Of course, the latter step only occurs if the polymer has some affinity for the organoclay surface (a property of both MMT and the organic treatment) 


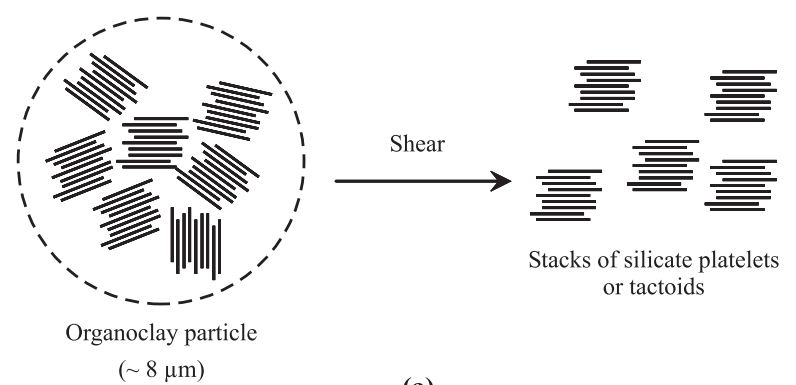

(a)

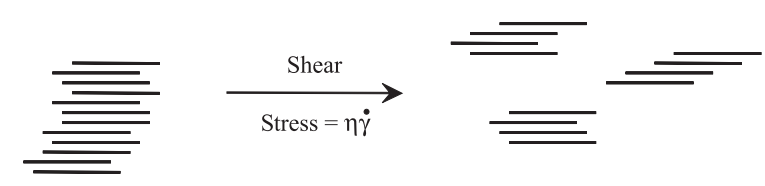

Shearing of platelet stacks leads to smaller tactoids

(b)

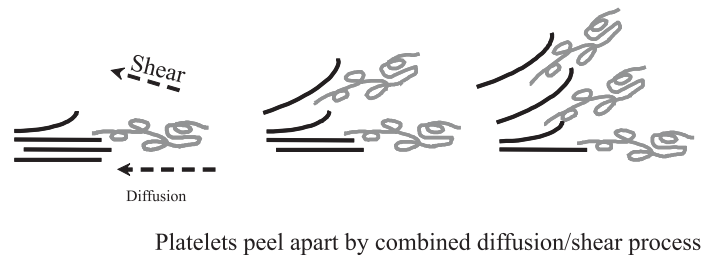

(c)

Figure 8. Proposed mechanism for exfoliation of organoclay during melt processing.

and requires time. This picture seems to account for a wide body of observations ${ }^{[11-13]}$ but needs to be refined and quantified.

\section{Thermal expansion behavior}

A major issue for polymers in engineering applications is to reduce the thermal expansion coefficient to achieve dimensional stability more comparable to metals. Numerous studies have examined how filler shape, size, and volume fraction influence the thermal expansion of polymer composites. Long fibers composites have a significantly lower linear thermal expansion coefficient than the matrix polymer. Polymer nanocomposites are also expected to have improved thermal expansion properties, while retaining the processing and surface characteristics of the matrix owing to the small size and low contents of the nano-filler.

Injection molded parts, especially composites, are anisotropic owing to the flow during fabrication. It is common to define three orthogonal coordinates to define the flow (FD), transverse (TD), and normal (ND) directions. The orientation of the clay platelets with respect to these axes has been determined for the nylon 6 nanocomposites using high resolution transmission electron microscopy (TEM) with the results summarized in Figure $9^{[14]}$. As can be seen the platelets are more well-aligned in the FD than TD while there is little alignment with the ND as expected from flow considerations. Figure 10(a) shows that small amounts of MMT significantly reduce the linear thermal expansion coefficient in the FD, more
FD Axis

- Some random orientation with preferential ordering along TD axis

- Slightly shorter lengths than in TD view

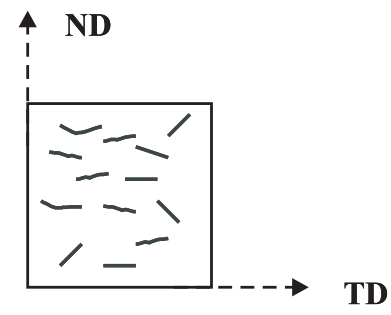

TD Axis

- Considerable alignment of platelet edges

- Some titled faces visible

- Slightly longer lengths than in $\mathrm{FD}$ view

\section{FD}

Figure 9. Orientation of clay platelets in nylon 6 nanocomposites as determined by TEM.

so for the better exfoliated nanocomposite based on high molecular weight (HMW) nylon $6^{[14]}$. The thermal expansion coefficient in the rubbery state $\left(\alpha_{\mathrm{r}}\right)$ appears to become equal to that below the glass transition $\left(\alpha_{\mathrm{g}}\right)$ at 6-7\% MMT. Figure $10(\mathrm{~b})$ shows that addition of clay reduces $\alpha_{\mathrm{g}}$ in the FD versus that in the TD; $\alpha_{\mathrm{g}}$ actually increases in the ND upon addition of clay. These results are consistent with the morphology as shown in Figure 9 and predictions by composite theory ${ }^{[14]}$.

\section{Effects of clay on nylon 6 crystallization}

One might expect that the small clay platelets would act as nucleating agents for crystallization for the nylon 6 matrix. Isothermal crystallization studies at $197^{\circ} \mathrm{C}$ reveals this to be the case at very low clay contents as shown in Figure $11^{[15]}$. Here the crystallization half-time, $\mathrm{t}_{1 / 2}$, of the nanocomposite is normalized by that of the extruded matrix polymer without any clay. Note that for pure nylon $6, \mathrm{t}_{1 / 2}$ increases with further addition of clay such that in the range of commercial interest, i.e., 3 to $5 \mathrm{wt} \% \mathrm{MMT}, \mathrm{t}_{1 / 2}$ for the nanocomposites is roughly the same as that of the base polymer. While clay apparently increases the number of nuclei, high clay loading retards polymer crystal growth.

Nylon 6 crystallizes in either of the $\alpha$ and $\gamma$ forms. Formation of the $\gamma$-type crystals is favored by low temperatures, stress, and to some extent the presence of clay $^{[15]}$. For injection molded bars, the $\gamma$-form predominates in the skin, while a mixture of $\alpha$ and $\gamma$ exist in the core, see Figure 12. The effect of crystalline morphology, as influenced by the presence of clay, on properties is under investigation. 

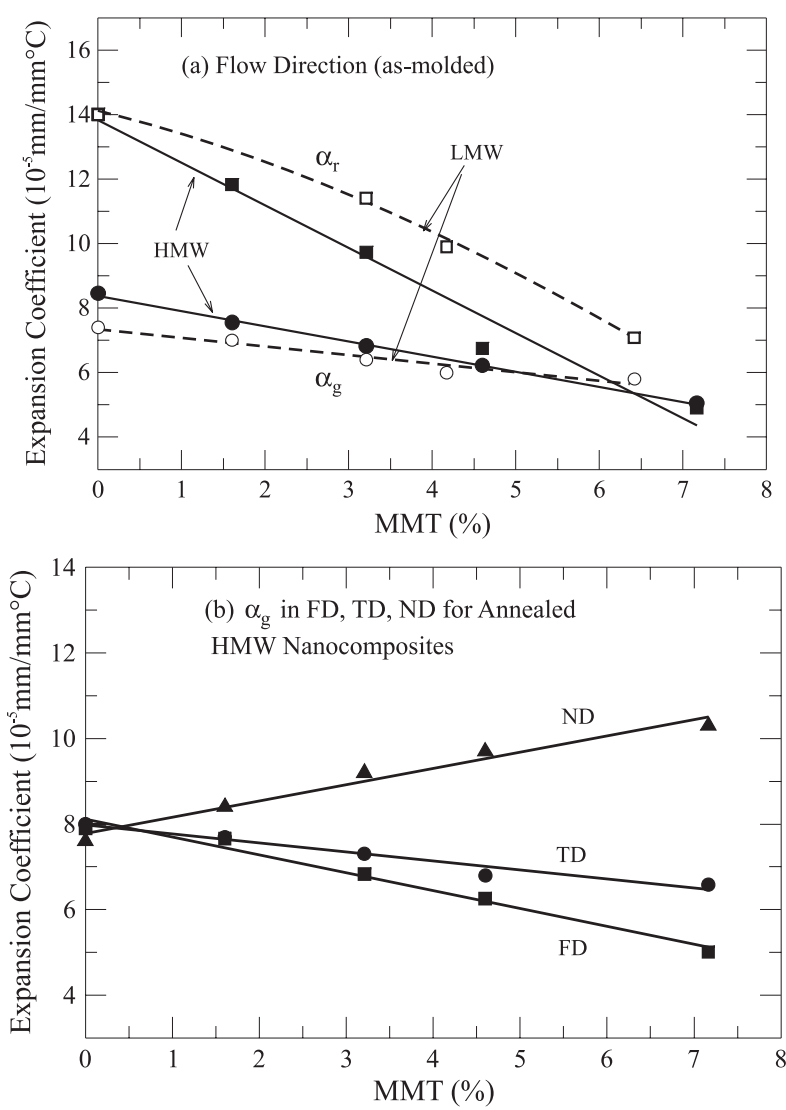

Figure 10. Hermal expansion coefficient of nanocomposites made by melt processing; (a) effect of molecular weight of the nylon 6 matrix and content of montmorillonite (wt $\%$ of MMT) on linear expansion along the flow direction and (b) the linear thermal expansion coefficients in the glassy region for all three coordinate directions.

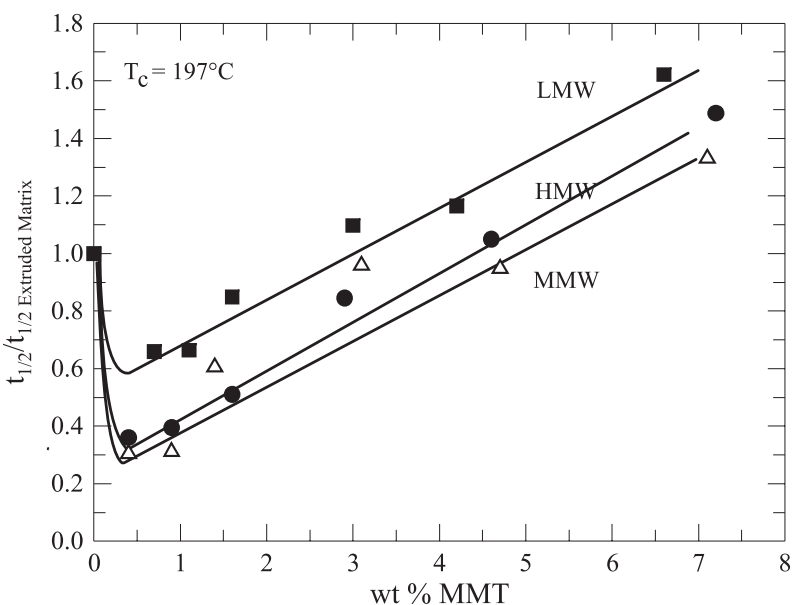

Figure 11. The effect of molecular weight of the nylon 6 matrix and content of montmorillonite on the isothermal crystallization behavior of nylon 6 nanocomposites, as defined by the half time to crystallization, $t_{1 / 2}$. The $t_{1 / 2}$ values are normalized by the half time to crystallization of the extruded matrix having no clay, $\mathrm{t}_{1 / 2-\text { Extruded Matrix }}$

\section{Comparison with composite theory}

A central question in nanocomposites is the extent to which the observed property enhancements, like modulus, can be explained by conventional ideas of reinforcement as predicted
Crystalline Structure

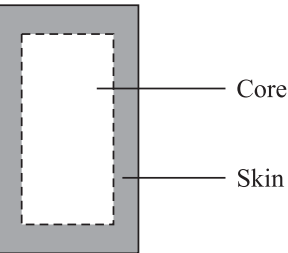

Cross Section of an Injection Molded Specimen (a) Determined via WAXD

(b) Determined via DSC

\section{Type (a) $\quad \%$ Crystallinity ${ }^{(b)}$ \\ $\alpha+\gamma \quad$ Pure $>$ Nanocomposite \\ $\gamma \quad$ Pure $<$ Nanocomposite}

Figure 12. Crystalline structure observed in injection molded nylon 6 nanocomposites.

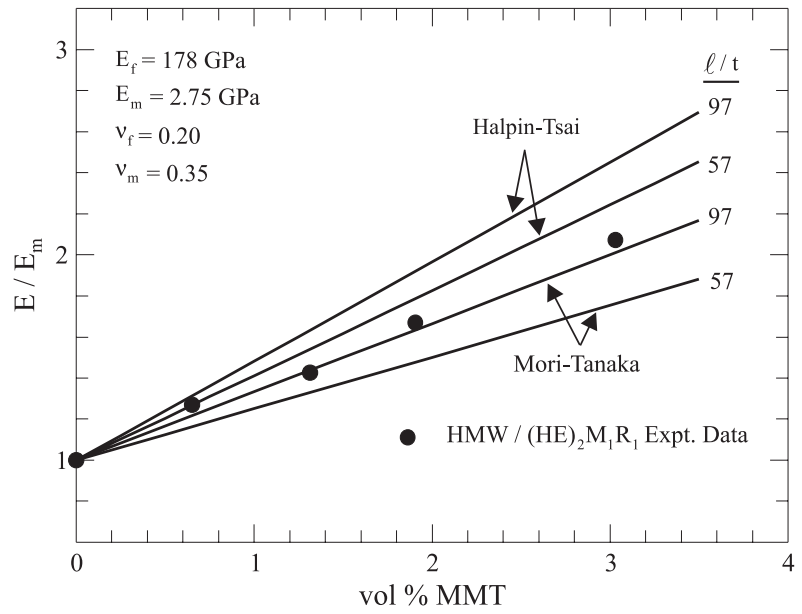

Figure 13. Comparison of the experimentally measured modulus of the nanocomposites, $\mathrm{E}$, relative to that of the matrix, $\mathrm{E}_{\mathrm{m}}$, with predictions made by the theories of Halpin-Tsai and Mori-Tanaka. An aspect ratio, $\ell / \mathrm{t}$, of 57 correspond to the experimentally determined value, whereas 97 corresponds to the aspect ratio if the clay platelets were perfectly exfoliated.

by composite theories like those of Halpin-Tsai ${ }^{[16,17]}$ or MoriTanaka ${ }^{[18,19]}$. Recent work has provide some insights into this question ${ }^{[20]}$ These two theories differ in how they treat the filler and how they approximate its effect on the composite. Careful TEM analysis showed that the average aspect ratio (platelet length or diameter/thickness of a platelet or stack of platelets $=\ell / \mathrm{t}$ ) of the MMT platelets in HMW nylon 6 nanocomposites is 57, while a value of 97 would exist if all the platelets were individually isolated.

Figure 13 compares the experimentally measured modulus of the composites (relative to that of the matrix polymer, $\mathrm{E}_{\mathrm{m}}$ ) versus volume $\%$ MMT with that predicted by the two theories for the two aspect ratios from TEM mentioned above. The predicted lines for $\ell / t=57$ lie slightly above the experimental data in the case of the Halpin-Tsai theory, while the MoriTanaka theory predicts lower values ${ }^{[20]}$. Based on this, it appears that within all the uncertainties involved in this comparison (experimental determination of morphology, which theory is more appropriate, etc.) the experimental results are captured rather well by simple notions of reinforcement.

Dynamic mechanical properties of these composites were determined for assessing the effect of clay on the heat distortion temperature (HDT) as determined by the method of Scobbo ${ }^{[21]}$. Figure 14(a) shows how the storage modulus, E', responds to 

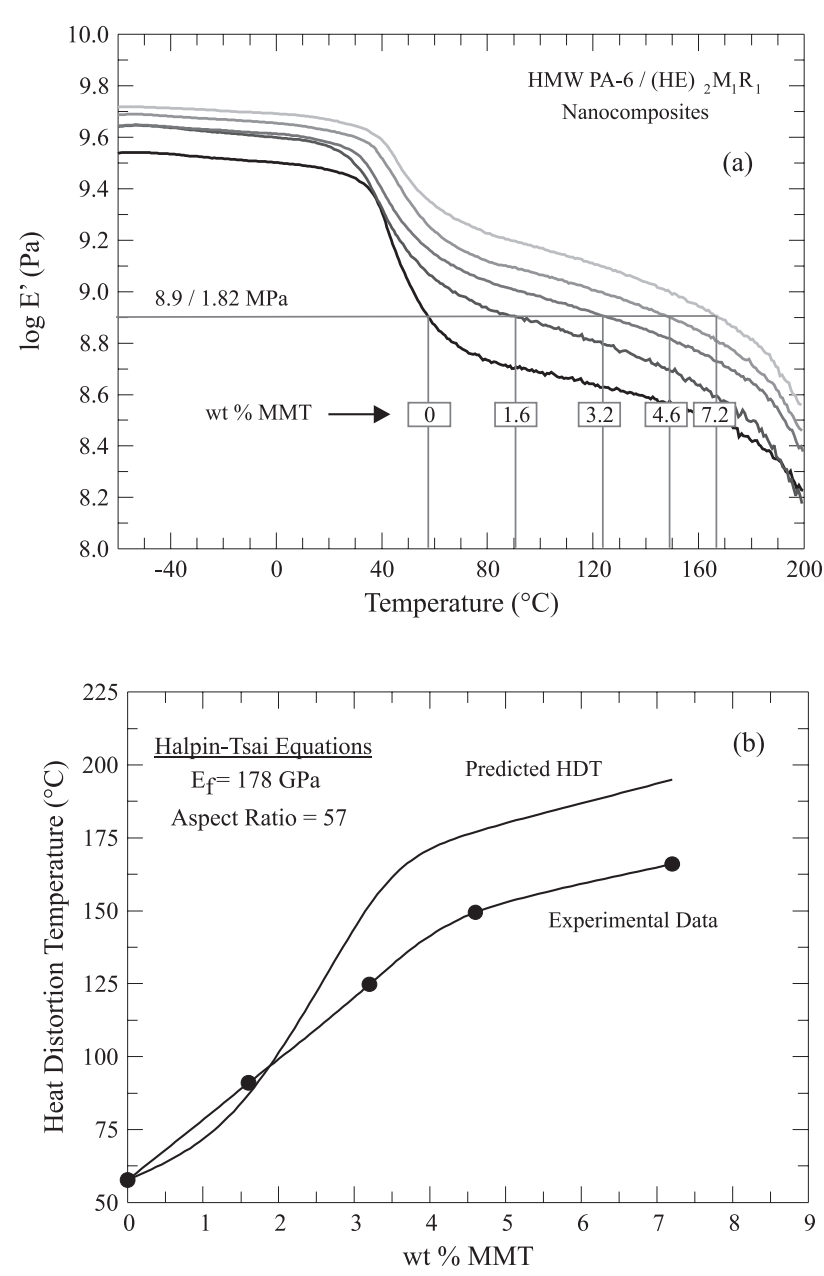

Figure 14. Dynamical mechanical properties of nylon 6 nanocomposites. (a) The effect of montmorillonite on nanocomposite storage modulus; vertical lines correspond to estimated heat distortion temperatures. (b) Comparison of experimental heat distortion temperatures with values predicted using the theory of Halpin-Tsai

clay addition. The vertical lines indicate the HDT values for a stress of 1.82 MPa. These values are plotted versus wt \% MMT in Figure 14(b). Addition of clay causes a remarkable increase in HDT which drives considerable industrial interest in nanocomposites. The prediction by the Halpin-Tsai theory is shown for comparison. The theory does a relatively good job of capturing the trend except at high clay loadings. The deviation between theory and experiment may be due to some of the morphological issues mentioned earlier ${ }^{[20]}$.

\section{Acknowledgements}

This work was supported by the Air Force Office of Scientific Research. The authors would like to thank Southern Clay Products Inc. for providing clay materials, WAXD analyses, and for many helpful discussions.

\section{References}

1. LeBaron, P. C., Z. Wang \& T. J. Pinnavaia- Appl. Clay Sci., 15(1-2), pp.11-29 (1999).
2. Pinnavaia, T. J. \& G. W. Beall - "Polymer-clay nanocomposites", Wiley series in polymer science, New York (2000).

3. Alexandre, M. \& P. Dubois- Mater. Sci. Eng., Rev., R28(12), pp.1-63 (2000).

4. Van Olphen, H. - "An introduction to clay colloid chemistry : for clay technologists, geologists, and soil scientists", 2d ed. Wiley, New York (1977.)

5. Fornes, T. D., P. J. Yoon, D. L. Hunter, H. Keskkula \& D. R. Paul- Polym., 43(22), pp.5915-5933 (2002).

6. Lan, T., P. D. Kaviratna \& T. J. Pinnavaia- Chem. Mater., 7(11), pp.2144-50 (1995).

7. Vaia, R. A. \& E. P. Giannelis- Macromol., 30(25), pp.79907999 (1997).

8. Vaia, R. A. \& E. P. Giannelis- Macromol., 30(25), pp.80008009 (1997).

9. Usuki, A., Y. Kojima, M. Kawasumi, A. Okada, Y. Fukushima, T. Kurauchi \& O. Kamigaito- J. Mater. Res., 8(5), pp.1179-84 (1993).

10. Cho, J. W. \& D. R. Paul- Polymer, 42(3), pp.1083-1094 (2001).

11. Dennis, H. R., D. L. Hunter, D. Chang, S. Kim, J. L. White, J. W. Cho \& D. R. Paul- Polym, 42(23), pp.95139522 (2001).

12. Fornes, T. D., P. J. Yoon, H. Keskkula \& D. R. Paul- Polym, 42(25), pp.09929-40 (2001).

13. Fornes, T. D., P. J. Yoon, H. Keskkula \& D. R. PaulPolym., 43(7), pp.2121-2122 (2002).

14. Yoon, P. J., T. D. Fornes \& D. R. Paul- Polym., 43(25), pp.6727-6741 (2002).

15. Fornes, T. D. \& D. R. Paul- Polym., 44(14), pp.39453961 (2003).

16. Halpin, J. C. \& J. L. Kardos- Polym. Eng. Sci., 16(5), pp.344-52 (1976).

17. Halpin, J. C., K. M. Finlayson \& J. E. Ashton - "Primer on composite materials analysis", 2nd, rev. / ed. Technomic Pub. Co., Lancaster, Pa. (1992).

18. Mori, T. \& K. Tanaka- Acta Metallurgica, 21, pp.571-4 (1973).

19. Tandon, G. P. \& G. J. Weng- Polym Comp, 5(4), pp.327333 (1984).

20. Fornes, T. D. \& D. R. Paul- 44(14), pp.4993-5013 (2003).

21. Scobbo, JJ, - "Thermomechanical Performance of Polymer Blends", in: Polymer Blends: Formulation and Performance, ch. 29, vol 2., Paul,D.R. \& Bucknall, C.B. (ed.), John Wiley, New York (1987). 